\title{
Comunidad humana y Humanismo ${ }^{1}$
}

\author{
Community human y Humanism
}

Mg. Marcos Elizondo Vega ${ }^{2}$ Universidad de La Serena, Chile

Recepción: 05 de noviembre del 2020

Evaluación: 15 de noviembre del 2020

Aceptación: 20 de noviembre del 2020

1 El presente artículo fue escrito en el marco del trabajo de investigación en el Centro Interdisciplinario de Estudios Latinoamericanos (CIEL), La Serena, IV Región de Coquimbo, Chile.

2 Actualmente es Coordinador de la Cátedra Internacional de Educación Intercultural: Rodolfo Kusch, perteneciente al Centro Interdisciplinario de Estudios Latinoamericanos (CIEL) de la Universidad de La Serena. Magister en Estudios latinoamericanos y Magister en Educación.

Correo electrónico: melizondo@userena.cl.

Elizondo Vega, M. (2020). Comunidad humana y Humanismo.

Cuestiones de Filosofía, 6 (27), 55-74. 


\title{
Resumen
}

El propósito de este trabajo es reflexionar en torno a la experiencia políticocultural del Humanismo, a partir del cuestionamiento levinasiano acerca de la experiencia humana como fuente de sentido. La tesis que el artículo plantea consiste en repensar la novedad de la comunidad humana, que inaugura el tratamiento de la experiencia de sentido que renuncia a la subjetividad como criterio hegemónico del Humanismo del siglo XX. Dicha renuncia nos lleva a reubicar al Humanismo en los márgenes del sentido (frontera) en que se interroga por la experiencia humana como propósito y finalidad fundante de un Humanismo del siglo XXI, sospechando que el concepto de Humanismo queda reducido a la experiencia de un sujeto político hegemónico característico del siglo pasado. En este sentido, la invitación es a repensar el Humanismo como posibilidad para situar a la comunidad nuevamente como centro orientador (ético) de resistencias ante las demandas políticas contemporáneas.

Palabras clave: Comunidad, subjetividad, humanismo, impropiedad, dessubjetivización, exterioridad.

\begin{abstract}
The purpose of this essay is to reflect on the political-cultural experience of Humanism, based on Levinas' questioning of human experience as a source of meaning. The thesis that the article raises consists of rethinking the novelty of the human community as it inaugurates the questioning of the experience of meaning that renounces subjectivity as the hegemonic criterion of 20th century Humanism. This renunciation leads us to relocate Humanism from the margins of meaning (frontier) in which human experience is questioned as the founding purpose and purpose of a Humanism in the 21st century, suspecting that the concept of Humanism is reduced to the experience of a hegemonic political subject characteristic of the last century. In this sense, the invitation is to rethink Humanism as the possibility of repositioning the community as a guidance (ethical) center of resistances in the face of contemporary political demands.
\end{abstract}

Keywords: Community, subjectivity, humanism, impropriety, desubjectivization, exteriority. 
(...) la comunidad es la gran ausente de la metafísica del sujeto, vale decir -individuo o Estado total- de la metafísica del para-sí absoluto: lo que también significa la metafísica del absoluto en general, del ser como ab-soluto, perfectamente desprendido, distinto y clausurado, sin relación.

Jean Luc-Nancy (2000, p. 16)

\section{La alteración de la experiencia humana}

Después de la primera mitad del siglo XX, cuando la "idea de lo humano y el hombre mismo" murieron en un campo de concentración -tal como lo expresara Elie Wiesel (1996)-, todo lo que valorábamos o pensábamos como 'civilización' o 'humanidad', alteró la comprensión de la experiencia humana al grado de hacernos cuestionar dicha experiencia como fuente de sentido (Levinas, 1993a, pp. 9-13).

La preocupación que surge ya no queda reducida a la acción del Yo y a la pasividad del Tú. La experiencia y la alteridad acontecen antes que la constitución del Tú por parte de nosotros, e incluso antes de la percepción que logramos de ella. En la experiencia se altera el sentido. La incertidumbre y labilidad de la experiencia de la alteridad "contrae el sentido" de un referente, de un significante sin significado; en el decir levinasiano es una 'huella que orienta'. La experiencia se orienta hacia la alteración, quedando ex-puesta la (in)significante alteridad de 'lo humano' que hay en ella.

Estas palabras inician con el recuerdo de la crítica de Levinas a la constitución interna del Humanismo. Una crítica a la constitución del "sujeto pensante"; aquél que cifra el mundo en el entendimiento de que "No hay vida alguna que signifique fuera de la verdad que él sirve y en la que se muestra. El resto de lo humano le es ajeno" (p. 12). Toda idea de experiencia humana que posea como sostén la constitución de un sujeto que se refiere a sí mismo para comprender 'lo ajeno', devela su particular carácter totalitario, no sólo presente a nivel histórico-social, sino también ético-político.

\section{EI Sujeto del Humanismo}

Es necesario reubicar al humanismo en torno al cuestionamiento de la experiencia humana, repensar sus propósitos, su finalidad, y comenzar a sospechar que tras la palabra 'humanismo' existe solo un actor, un personaje, que alcanzará protagonismo desde la época moderna hasta hoy: hablamos del sujeto político. 
Podríamos coincidir con Foucault (2002) y pensar que la construcción de la idea de sujeto es fruto de un orden epistémico que "hace posible los conocimientos y las teorías, el suelo de positividad en que asientan los códigos fundamentales de una cultura, así como las teorías científicas y filosóficas que pretenden explicar tales códigos" (Castro, 2008, p. 50). Con este horizonte epistémico de fondo, el pensador francés advirtió que es en la genealogía del binomio saber/poder desde donde el sujeto se constituye socialmente. Ya Hobbes, en el siglo XVII, había señalado que la relación entre el Estado y la sociedad se sostiene sobre la base del binomio poder/ miedo (Korstanie, 2009). La relación primaria entre un ser humano y otro, el saber, desde esta perspectiva, será sólo una consecuencia de la Ilustración. Para el político inglés "La vida -primera necesidad-sólo puede asegurarse acumulando poder - la primera pasión. Pero sólo a expensas de los demás puede acumularse poder: a costa de $s u$ vida" (Esposito, 2003, p. 64).

En este sentido, el orden epistémico no sólo abarca la constitución de la idea de sujeto sino también la idea de sociedad, y "tiene como tema capital la identificación del actor social con sus obras y su producción, ya se trate del triunfo de la razón científica y técnica, ya se trate de las respuestas racionalmente aportadas por la sociedad a las necesidades y a los deseos de los individuos" (Touraine, 2006, p. 36). No ha de extrañarnos que la comprensión de dicho sujeto recaiga sobre la política y la economía, donde la supervivencia es la meta común de todo poder y, por tanto, la 'situación central': la subsistencia del sujeto. Esta 'situación central' será la órbita desde la cual la 'calidad de sujeto' comienza a develar una inconsistencia a nivel de sus fundamentos. Su inicial subjetividad y libertad quedan sustraídas a la condición de sujeto social, desde donde se piensa en la natural sociabilidad del hombre.

Hobbes (2005) llegará a la conclusión de que las sociedades no se han originado en la benevolencia recíproca, sino en el temor mutuo: el miedo a la muerte. En adelante el sujeto será una suerte de 'condensador sustancial', es decir que concentra, comprime su subjetividad y libertad en el "poder que articula el miedo", que se materializa en la invasión política de la vida (individual y social). Ambas situaciones se esgrimen como el fundamento esencial de la constitución de una comunidad humana (sociedad), y se expresan (estratégicamente) en la normalización de la vida, en la que:

el miedo no se debe confinar al universo de la tiranía y del despotismo; por el contrario, es el lugar fundacional del derecho y la moral en el mejor de los 
regímenes. En suma, el miedo -al menos potencialmente- tiene una carga no sólo destructiva, sino también constructiva. No determina únicamente fuga y aislamiento, sino también relación y unión. No se limita a bloquear e inmovilizar, sino que, por el contrario, impulsa a reflexionar y a neutralizar el peligro: no está del lado irracional, sino del lado de la razón (Esposito, 2003, p. 57).

El control (poder) racional del miedo es lo que nos recuerda Hobbes (1980). El poder articulado en una "política del miedo" tiene como único correlato una política de la muerte, una tanatopolítica. No ha de sorprendernos, entonces, que para Hobbes sólo disociándose (des-socializándose) es posible un principio de liberación -librarse de la muerte- de todo lo que está ligado; en otras palabras, lo que une a toda sociedad (socio-política) es la desvinculación entre los seres humanos (comunidad), prevaleciendo así el control de la vida/muerte del otro: "El Estado es la des-socialización del vínculo comunitario" (Esposito, 2003, p. 66), en el que se anula la alteridad como un plano vinculante en la experiencia humana: frente al 'otro' mi vida está en constante peligro.

\section{La 'situación central'}

El peligro de vivir y la muerte serán los temas histórico-políticos a partir de los cuales se inicia el cuestionamiento de la constitución de este sujeto racional y su conformación social, apuntando a que la experiencia humana (social) sea convertida en una metafísica del sujeto por excelencia. Para Esposito será "un sujeto que deja ser al ser" (2003, p. 66), un sujeto que hace de sí mismo (poder) la medida de todas las cosas. El sujeto que puede 'hacer ser', sólo necesita de sí para ser. La experiencia humana no es más que la constitución del sujeto mismo, por lo que la única referencia de experiencia humana es siempre él mismo (prevaleciendo una idea sustancialista-inmanentista-del sujeto). El poder económico de este mecanismo busca simplificar la relación humana a un solo sujeto. Es decir, la relación que niega la relación -al igual que Hobbes-, donde nuestro único sustento en la sociedad (comunidad) es la negación de la relación que establecemos 'con' y 'en ella', por miedo a la muerte: una unidad social sin vínculo.

La cuestión de la 'situación central' (subsistencia del sujeto) es que la relación entre los seres humanos no puede quedar reducida al miedo recíproco. Lo común se ha convertido en un espacio vacío; una fantasmagoría, puesto que la relación entre seres humanos sólo se sostiene sobre la base de la destrucción 
de la relación misma: la necesidad de ser sujeto se asienta en el poder de la construcción de su subjetividad. Esta 'necesidad de ser' será el gran tema ontológico del siglo pasado, mientras que el 'poder ser' será el tema éticopolítico en el que, sin embargo, la subjetividad seguirá siendo vista como 'situación central', tanto política como ontológicamente.

Sin duda que tras lo vivido y experimentado durante y posteriormente a la Segunda Guerra Mundial, la 'situación central' adquirió tal banalidad como bien lo interpretara Hanna Arendt (2003)-, que puso en entredicho todo lo que ha sido construido por el Sujeto. Para Foucault (2000), de esto se desprende no solamente la relación entre saber y poder, sino que también el sometimiento a la obediencia hace que el sujeto se transforme en un cuerpoindividuo, una 'máquina de producción'. La subjetividad queda reducida a un cuerpo/objeto instrumental, del mismo modo que el cuerpo social a un mecanismo de reproducción (anatomopolítica). La libertad constituyente del individuo es una constante lucha por la subsistencia sistémica, como en la antropología hobbesiana, destinada a continuar reproduciendo la máquina de la muerte para así "poder seguir viviendo".

En este plano el Humanismo no es más que otro gran espectáculo de la civilización en torno a una política socio-cultural, que deja a la subjetividad y a la libertad engrilladas a un orden epistémico, al poder de saber 'lo que es bueno para el ser humano’. El Humanismo se reterritorializa (Deleuze, 1985) al pasar del ámbito ético al ámbito de la política, que pasa a gobernar la vida humana y, con ello, a constituirse como biopoder. La dinámica del biopoder (cuerpo-individuo, cuerpo-especie) presente al interior de la "naturalización (política) del Humanismo" es un conjunto de estrategias de saber y de relaciones de poder que se articulan desde el siglo XVIII: cuando comienza a utilizarse lo biológico como componente de una tecnología política. La construcción del humanismo tiene como finalidad 'calificar, medir, apreciar y jerarquizar acorde a una norma'. La “norma” demarcará aquello que será comprendido como producción social y como algo constituyente de las relaciones sociales (humanidad).

La interpretación de Foucault nos lleva a pensar que si bien las épocas moderna y contemporánea están insertas en el biopoder, esto debe ser entendido como una estructura versátil que fluctúa sobre formas más o menos acabadas de 
gobernar la vida (Larraín, 2010, p. 68)³. No será extraño, en este contexto, el nacimiento de la ciencia jurídica, que hará su inserción en la escena política como "garante", "observador" y "juez" de estas normas: "En otras palabras, la tecnología del poder centrada en la vida se sirve de la norma para realizar una demarcación extensa de los cuerpos y de las poblaciones. Su efecto principal es la articulación de una sociedad normalizadora" (Castro, 2008, p. 327). El Humanismo se desprende de todo trascendentalismo para reducirse a la expresión de una conducta normal, común a todo sujeto social. El Humanismo se reduce a una estrategia política de control, y por ello establece los márgenes de seguridad necesarios dentro de los límites biopolíticos que resguardan la integridad (subsistencia) epistémica creada por el sujeto, es decir que la experiencia humana queda reducida a una 'conducta humana' regulada por un principio de valoración económico: la utilidad que posee una vida valiosa para la producción de un cuerpo social y otra de menor valor.

\section{El Humanismo del Sujeto}

Quizá no existe una mayor evidencia de esto que la Declaración Universal de los Derechos Humanos. Ella es, sin lugar a dudas, cuando hablamos de Humanismo, el acontecimiento filosófico-político por excelencia del siglo XX. No sólo porque trata acerca de la libertad, la justicia y la paz en el mundo como atributos indiscutibles del desarrollo humano, sino también porque subordina a ellos la dignidad y el valor de la persona. Sin embargo, esto no sería comprensible si dicha declaración no poseyera una "base de legalidad" o de "derecho" que asegure y resguarde dichos principios. Sólo de esta manera los Derechos Humanos pueden convertirse en estandarte de la lucha por una comunidad política que asuma en "propiedad" la idea unificante del ser humano (Humanismo) en el siglo XX.

Lo que señala dicha declaración son los atributos, las determinaciones y los predicados que califican a "alguien" como "valioso", en la medida en que este 'alguien' afirme estas características y se comprenda así mismo poseyendo dichos atributos. De una u otra forma, es un contrato moral, la constitución de una comunidad (humanidad) que tiene como "testigo de fe" a la Moral y al Derecho en la ceremonia civil de la historia humana. En este sentido,

3 El sociólogo chileno Jorge Larraín señala (interpretando a Foucault) que "Desde el siglo XVIII el poder ha cambiado en el sentido de que su ejercicio ya no es más puramente 'desde arriba', sino también 'desde dentro' del cuerpo social” (2010, p. 68). 
parece comprensible pensar que ante la destrucción del ser humano -como lo ocurrido en la Shoa o en las dictaduras latinoamericanas, por dar sólo dos ejemplos-, el único mecanismo político posible era "afirmar" al sujeto político, es decir, afianzar la 'persona jurídica' para evitar su destrucción, evitar la muerte del Derecho a ser 'ser humano'. El Estado y la comunidad internacional serán los garantes, los protectores de dichos derechos. Si ello no se cumpliera, los Derechos Humanos serían inútiles: allí donde el "estado de excepción" es la regla, tal como nos lo dijera Walter Benjamin en su tesis VIII de la historia (2002, p. 53), no sólo se anulan los derechos, sino también el ser humano.

La unificación axiológica y jurídica que se establece, surge con el deseo de no repetir nuevamente la historia y la 'experiencia (in)humana'. Para ello se hace imprescindible crear un "tratado" que una, ligue o vincule a las naciones, con la intención de apreciar y juzgar el cumplimiento de la idea de ser humano a la que se ha llegado por acuerdo. El Humanismo pasa a ser un dispositivo de poder, en el que la comunidad de naciones sustancializa 'lo humano', a un sujeto-humano (cuerpo-especie). Con dicha Declaración, el sujeto de Derecho antecede a 'lo humano': un sujeto garantista de libertad, justicia y paz para todos - como una consigna eleccionaria-, un sujeto constituyente de valores -como un fundamento histórico-filosófico-, un sujeto que llevará al Humanismo -como un 'hijo pródigo'- a la trinchera política. El Humanismo se convierte en un simulacro de 'lo humano', puesto que agrega sustancialmente al sujeto político el atributo de "humano': "ser humano" -no sólo como especie, sino también socialmente-, será entonces sinónimo de ser 'más sujeto': la metonimia de 'lo humano'.

El sujeto no es ya solamente una entidad individual, sino que pertenece a una entidad mayor, superior o mejor, que se origina en la constitución de dicho sujeto de Derechos Humanos. En otras palabras, este Humanismo no es más que el regreso a lo-mismo que 'ser-sujeto'. Toda diferencia es un simple agregado en el banquete que celebra el ser 'más sujeto'. Lo común al humanismo de este sujeto es anteponer la representación de una subjetividad constituyente de verdad. La 'diferencia' (lo diferente, distinto, otro), en este sentido, adquiere la forma de una metáfora de la alteridad que adquiere una fuerza simbólica inusitada, puesto que se mueve e irrumpe en la desconstitución de la subjetividad, transformándose (bajo la perspectiva del sujeto constituyente) en un enemigo. 
El 'sujeto humano' se 'altera' en la diferencia, y en esta alteridad se desconstituye. La experiencia humana queda sobredeterminada bajo la condición de amigo o enemigo de la diferencia. Dicha sobredeterminación es la valoración central de la tanatopolítica, que adquiere su carta de ciudadanía con la economía política del sujeto.

\section{Comunidad de Sujetos}

Ante la incertidumbre que propicia la alteridad, la trinchera subjetiva dirigió sus esfuerzos al fortalecimiento de un tipo de humanismo, y en ella nos identificamos todos, puesto que en ella establecemos nuestro vínculo identitario (subjetivo), es decir fortalecemos "una comunidad que sigue atada a la semántica del propium" (Castro, 2008, pp. 23-24).

La identidad surge en la comprensión de la autoconstitución, lo que es 'propio de todo sujeto': “es común lo que une en una única identidad a la propiedad -étnica, territorial, espiritual- de cada uno de sus miembros. Ellos tienen en común lo que les es propio, son propietarios de lo que les es común” (p. 25). No ha de extrañarnos, por tanto, que la "comunidad de naciones", la "comunidad científica", la "comunidad ecológica" o la "comunidad filosófica", asuman este mismo principio de identidad: la pertenencia de lo común que los une $\mathrm{e}^{4}$. En este tenor, una 'comunidad' es un 'contrato' político-económico entre los

${ }_{4}$ Roberto Esposito, quien ha trabajado la etimología de esta palabra, señala una paradoja, puesto que el significado que atribuimos actualmente al sentido de 'lo común' (que hace al Humanismo, a las comunidades, a los movimientos sociales), difiere de su historia: "En todas las lenguas neolatinas, y no sólo en ellas, «comun» (commun, comune, common, kommun) es lo que no es propio, que empieza allí donde lo propio termina (...) Es lo que concierne a más de uno, a muchos o a todos, y que por lo tanto es «público» en contraposición a «privado», o «general» (pero también «colectivo») en contraste con «particular»" (Esposito, 2003, pp. 25-26). Sin embargo, Esposito pondrá más atención a un segundo significado que, según él, "traslada a su interior la complejidad semántica mayor del término [común] del que proviene: munus (arc. moinus, moenus) compuesto por la raíz mei- y el sufijo -nes, que indica una caracterización social" (p. 26). Dicha caracterización social provee el significado de este término de acuerdo a su uso contextual; por esta razón no se trata de un significado homogéneo, aunque pueda remitirse a la idea de "deber". Las caracterizaciones son "onus, officium, donum" (p. 26). Será precisamente esta última caracterización la que orientará la reflexión de Esposito hacia la "especificidad del don que expresa el vocablo munus" (p. 26), pues según su perspectiva, cumple una doble función. 1) Tiene "el efecto de reducir la distancia inicial" (p. 26), refiriéndose a la distancia que se observa en la yuxtaposición entre lo público/privado de la primera definición; 2) nos permite "realinear también esta significación con la semántica del deber" (pp. 26-27). Esposito señala al respecto: "una vez que alguien ha aceptado el munus, está obligado (onus) a retribuirlo, ya sea en términos de bienes, o en términos de servicio (officium)" (p. 27), mientras que en la tercera acepción (donum) se hace referencia al "don que se da porque se debe dar y no se puede no dar", es decir, a una pérdida que "No implica de ningún modo la estabilidad de

Elizondo Vega, M. (2020). Comunidad humana y Humanismo.

Cuestiones de Filosofía, 6 (27), 55-74. 
intereses y las necesidades de la subjetividad, y de la satisfacción y seguridad del desarrollo de ella misma. La comunidad es un mecanismo de subsistencia (defensa) ante la alteridad, hasta llegar a transformar este principio en una filosofía política sobre la vida.

Para Roberto Esposito "La comunidad no es un modo de ser -ni menos aún, de 'hacer'- del sujeto individual. No es su proliferación o multiplicación. Pero sí su exposición a lo que interrumpe su clausura y lo vuelca hacia el exterior, un vértigo, una síncopa, un espasmo en la continuidad del sujeto" (2003, p. 32). El munus contenido en la base de la communitas: "No es una posesión sino, por el contrario, una deuda, una prenda, un don-a-dar" ( $p$. 30). Es decir, lo que está en juego no es la propiedad de nuestra subjetividad, sino más bien su donativo. En una comunidad no somos dueños de nosotros mismos, "no es lo propio, sino lo impropio -o, más drásticamente, lo otrolo que caracteriza a lo común" (p. 31). En este sentido, no encontramos un principio de identificación, sino el extrañamiento que nos hace estar ausentes de nosotros mismos. Somos una entidad ausente de lo propio, es decir, impropios (impropiedad radical): una 'filosofía de la intemperie', en el decir de Nerva Bordas (1977), que se presenta y "penetra en su común nopertenecerse" (Esposito, 2003, p. 32): lo común "empieza allí donde lo propio termina" (pp. 25-26).

Es por esto que se puede afirmar que la comunidad comienza en la desconstitución del sujeto: en 'algo que tiene que darse', un 'don-a-dar' que altera nuestro existir. La subjetividad pierde existencia y, por tanto, consistencia, quedando solo 'lo existente' ex-puesto a un mero "estar vivo". Entre la existencia y lo existente se extiende el paisaje de la diferencia: "el desierto de lo real", donde lo existente se haya deshabitado de existencia.

\section{Comunidad sin sujeto}

Para Emmanuel Levinas, la radicalidad de la experiencia humana comienza en el hecho de que seamos arrojados a la existencia, cuando sólo hay existente: "Es como si al existente no apareciese más que una existencia que le precede, como si la existencia fuese independiente del existente y el existente que se halla arrojado no pudiese jamás convertirse en dueño de su

una posesión -y mucho menos la dinámica adquisitiva de una ganancia-, sino pérdida, sustracción, cesión: es una 'prenda', o un 'tributo', que se paga obligatoriamente” (p. 28). 
propia existencia" (Levinas, 1993b, p. 83). En el hay, no somos dueños de nuestra propia existencia, sino que más bien, hay abandono y desamparo. La soledad en la que se ve envuelto nuestro existir, será el centro orientador de la problemática levinasiana: ligar lo arrojado (existente) al mundo (existencia).

\section{El existir sin existente es}

algo sin intencionalidad, sin relación" (p. 80); es la "unidad indisoluble entre el existente y su acción de existir (...) La soledad procede del hecho mismo de que hay existentes. Concebir una situación en la que la soledad fuera superable significaría experimentar el principio mismo del vínculo que liga al existente a su existir (p. 82).

En otras palabras, ¿esto significaría que no sólo hay existir o existentes, sino que también hay acontecimientos en los cuales el existente contrae la existencia? El llamado del pensador lituano es a cuestionar la idea de identidad que el sujeto esgrime en su existir, aquel "existir que es controlado por el existente idéntico a sí mismo, es decir, solo. Pero la identidad no es únicamente una salida de sí, sino también un retorno a sí mismo (...) La identidad no es una relación inofensiva consigo mismo, sino un estar encadenado a sí mismo” ( $\mathrm{p}$. 93).

Acorde con lo anteriormente señalado, podríamos aventurar a sostener que la comunidad no es constitutiva de sujetos, sino de 'existencia humana'; el ámbito donde el existente contrae la existencia. El existente se encuentra en un estado de indeterminación ('todavía-aún-no'), en una 'lógica vital de sentido inconfesable"s como la esperanza kafkiana, aquella que nos dice que

5 Es pertinente señalar la relevancia concreta y simbólica que adquiere el testimonio (la palabra del testigo). La 'lógica vital del sentido' de la que se habla, responde al momento de indeterminación en el que su existencia queda en cierta forma al margen de la lógica racional del sentido y, por tanto, 'desterritorializada' de la existencia que da sentido, en una suerte de 'intemperie ontológica', donde "hay sentido de la existencia" pero no para el existente. El testimonio, en consecuencia, no da cuenta de evidencias (existencia de evidencias) sino de realidad, no da cuenta de hechos sino de acontecimientos. El lenguaje es insuficiente: tiene demasiado sentido para decir lo que se vivió, no hay alfabeto para decir lo que no se sabe. Testimonio y testigo no sólo encarnan singularmente el valor de la memoria, sino que también el de la justicia, puesto que en ellos se condensa la situación última de un acontecimiento '(in)humano'. En Chile, por ejemplo, la "figura" del testigo ha sido el gran referente de verdad y de justicia una vez que se recupera la democracia (marzo de 1990) y comienzan a ser esclarecidas las vulneraciones a los Derechos Humanos durante la Dictadura Militar (1973-1990). De hecho, serán los informes de la Comisión Valech, (Comisión Nacional sobre Prisión Política y Tortura, 2010), y de la Comisión Nacional de Verdad y Reconciliación (Informe Rettig), creada con el objeto de contribuir al esclarecimiento global de la verdad sobre las

Elizondo Vega, M. (2020). Comunidad humana y Humanismo.

Cuestiones de Filosofía, 6 (27), 55-74.

doi: https://doi.org/10.19053/01235095.v6.n27.2020.12038 
hay infinitas existencias de esperanzas, sólo que no para nosotros: la crisis de la esperanza.

El existente es la contracción del sentido, un espasmo en la existencia. La 'contracción que contrae'; 'lo arrojado' que perturba la existencia que contrae a la experiencia histórica en 'lo común que hay en lo existente'. La experiencia histórica y "el mundo de la vida" se remontan al acontecimiento común de lo existente, alterarse para contraer existencia. Y es en esta "contracción", cuando:

(...) en la vida experimentada por los humanos sucede -de ahí es donde comienza lo humano propiamente dicho, pura eventualidad pero al mismo tiempo eventualidad pura y santa- el consagrarse-a-otro (...) ¡De otro modo que ser! Esta ruptura de la indiferencia (...) es la posibilidad del uno-para-elotro que constituye el acontecimiento ético (Levinas, 2001, p. 10).

Desde esta perspectiva, la comunidad no es un acontecimiento político, social ni histórico, sino que su orientación (sentido) será ética: el llamado a "recuperar" lo humano de la experiencia.

\section{Des-subjetivización del humanismo}

Según el pensamiento levinasiano un humanismo está decantado en la existencia humana que no lo funda. En el humanismo levinasiano, en consecuencia, hay una alteridad que pesa como experiencia de lo humano que se abre a la exterioridad de lo otro, donde la propia subjetividad queda expuesta y afectada por el Otro, una experiencia que subjetivamente no le es propia porque no la funda (Levinas, 1995, p. 244).

La tradición ha convertido al humanismo en "igualdad y semejanza" en torno al sujeto constituyente, remitiéndose a sí mismo en un eterno presente y cargando con el temor de la proximidad. El mundo deja de ser residencia y el tiempo es un presente que no hace acto de presencia; el humanismo es una existencia sin portador. En cierta forma es estar condenado a un 'mundo sin amor', de la misma forma como podría estar condenado un esquizofrénico (Dörr, 1996, pp. 99-117): la calidad de ser sujeto consiste en suspender 'la relación humana' de su propia subjetividad. La extrema soledad que nos

graves violaciones a los derechos humanos cometidas entre el 11 de septiembre de 1973 y el 11 de marzo de 1990. En ambas investigaciones serán los testimonios el principal sostén para pensar la reinterpretación oficial de este horizonte histórico. 
domina, es la soledad intrascendente, la soledad metafísica: quizá por este motivo, todos los esfuerzos de Levinas estaban inclinados a intentar 'reubicar' la metafísica en el plano de la ética, puesto que es en ella donde 'lo humano significa' la liberación del 'Sí mismo'.

En esta perspectiva, si la construcción de la subjetividad se im-pone en el mundo, no sólo señala una cuestión de estrategia político-histórica, sino también un dispositivo de poder en términos éticos. La ética se convierte en una im-posición subjetiva, transformándose de esta manera en un dispositivo de poder político-económico, en el que la totalidad de la existencia queda reducida a términos instrumentales. Es quizás aquí donde surge la idea de una liberación del humanismo (su des-subjetivización).

El humanismo levinasiano se dirige al Deseo ético de lo humano, y tiene su inicio en la experiencia del "estar ex-puesto al existir". Su pretensión no es que el sujeto decida autorrealizarse a través de una libertad absoluta (al modo de Hobbes). La libertad - del mismo modo que el Sujeto- no existe en la liberación, más bien queda ex-puesta en el Deseo del Otro; "uno-para-el otro" o en este 'don' que goza el cum de lo común -según la interpretación de Esposito-. Y es en este 'común deseo' donde surge la experiencia humana.

La significación que entrama el 'uno-para-el-otro', "Entre el uno que soy yo y el otro del que respondo, se abre una diferencia sin fondo, que es, también, la no-indiferencia de la responsabilidad, significatividad de la significación, irreductible a ningún sistema. No-indiferencia que es la proximidad misma del prójimo, a través de la que se perfila solamente un fondo de comunidad entre el uno y el otro (Levinas, 1995, pp. 12-13).

En otras palabras, 'lo humano' (no-indiferencia) hace la existencia humana (proximidad), del mismo modo como la 'liberación de Sí mismo' hace el 'uno-para-el-otro'. De acuerdo con lo anterior, tanto para Levinas como para Esposito, la discusión en torno al humanismo se ha escindido en dos interpretaciones, en las que no sólo se debe sospechar de la 'condición de sujeto', sino también cuestionar los fundamentos 'constitutivos' del 'ser sujeto': la construcción de una tanatopolítica (política de muerte), la indiferencia frente al mundo y su relación, la instrumentalización de la realidad concebida como cosa, el encadenamiento a sí-mismo, la 'apropiación' ('lo que pertenece al sujeto, o exclusivamente es 'propio de él'). La negatividad de un humanismo construido sobre la base del yo considerado como principio de identidad, igualdad, libertad. Es un humanismo que se fundamenta en la indiferencia de lo humano. 
Desde otra perspectiva, el humanismo comienza con el cuestionamiento acerca de la experiencia que le otorga su propio sentido. Este cuestionarse se orienta a juzgar la subjetividad constituyente del ser humano para abrirla al establecimiento de vínculos. Para Levinas el humanismo es un 'estar-enrelación': una experiencia de sentido de lo humano abierta a la exterioridad de lo otro, en la que esta exterioridad (lo Otro) demanda mi participación como responsabilidad. Para el pensador lituano el humanismo no se sostiene basado en la libertad o la verdad del ser humano, sino en la justicia, es decir, en la responsabilidad que nos compete a cada uno de nosotros. 'Estar-enrelación' es la responsabilidad que demanda el Otro. Y en este 'estar-enrelación-con-Otro' se esconde el deseo de 'un-más-allá-de-ser': 'lo humano' es lo 'absolutamente Otro', la ausencia misma del sujeto.

Considero que en este punto Esposito coincide con la concepción de la ruptura que se establece en el ámbito de la alteridad, y que constituye la posibilidad de la comunidad. La comunidad es la base de la política-humanista de Esposito. Bajo el concepto de communitas se esconde lo impolítico (el vaciamiento del espacio político, la desubjetivización del poder), que asume la realidad como conflicto (el poder del conflicto). El conflicto de la comunidad comienza antes de ser comunidad, es decir, en el instante en que dos seres humanos coinciden en que 'no hay nada en común'. Esto implica que la comunidad surge en la medida en que un 'existente cobra existencia' -en el sentido levinasiano. La instancia de la comunidad como estructura social o política, histórica o antropológica, es decir, como construcción epistémica a través de las perspectivas del conocimiento humano acerca de un fenómeno de nuestra realidad que definimos como comunidad, adquiere una distancia inusitada cuando la comunidad se convierte en un acontecimiento (vivencia) fundamental de la experiencia humana. En la comunidad se altera nuestra experiencia existencial, no somos dueños o propietarios de la comunidad para llegar a pensarla de esta manera. Según Esposito, la comunidad exige una 'donación', 'el precio que hay que pagar': la subjetividad, la prevalencia del yo sobre el otro.

Desde esta perspectiva el Humanismo es un cuestionamiento de la experiencia que hace posible 'lo humano', una experiencia que ad-vierte su contenido en la incertidumbre de la presencia. Con 'lo humano' no sabemos qué pasará. La significación de 'lo humano' precede a la subjetividad y sus datos, abriéndose a lo numinoso de la experiencia. El significado del humanismo no puede ser comprendido como un resplandor, sino más bien como la carga, el peso de toda 
la historia que se hace presente en él. Puesto que ya no reside sustancialmente en el yo (sujeto), sino en la exterioridad, 'lo humano' se mueve al "estarfuera-de-sí”, en la liberación de Sí mismo, en la experiencia que recobra el sentido de la liberación. En Levinas a la manera de una ética-metafísica; en Esposito bajo la forma de una teoría política.

El sentido que encarna la significación de 'lo humano', y que por tanto 'orienta' las relaciones humanas, "no indica un impulso, un fuera de sí hacia lo otro que sí, puesto que la filosofía insiste en absorber todo Otro (Autre) en Lo Mismo (Même) y en neutralizar la alteridad" (Levinas, 1995, p. 37). Esto lleva a pensar que "el ser se aligera de su alteridad" (p. 38) para poder constituir de esta manera su existencia. Lo que diagnostica Lévinas es el 'oscuro contrapunto de la historia de la civilización', que - a pesar de todo'nos mantiene unidos': 'La grieta, el trauma, la laguna de la que provenimos: no el Origen, sino su ausencia, su retirada. El munus originario que nos constituye, y nos destituye, en nuestra finitud mortal" (Dörr, 1996, p. 34).

Si la subjetividad no colma el deseo de lo humano, sino que más bien lo ahonda: ¿Es quizá al interior del munus donde puede ex-ponerse de la mejor manera la concepción de 'lo humano' en el pensamiento levinasiano? ¿En qué medida la comunidad es un acontecimiento tan radical que su experiencia antecede a la construcción de sociedad e incluso de ser humano?

La ausencia del Humanismo (a modo de conclusión):

Lear.

¿Dónde estoy? ¿Dónde he estado? ¿Pleno día?

Estoy tremendamente confundido.

Moriría de lástima si viera a otro

En el estado en que me encuentro yo.

Realmente no sé qué decir. (...)

Cómo poder saber lo que ocurre (Parra, 2004, p.168).

Entre la 'ausencia de sentido' y la 'pérdida de sí mismo' se sitúa la metafórica existencial de un Rey que podría ser cualquiera. 'Lo que ocurre' es el hecho de no-saber. No es suficiente todo lo que hay: hay más realidad que suficiencia de sentido. En 'lo que ocurre' hay más indeterminación que determinación. Entre el ¿“cómo poder saber lo que ocurre”? de Lear y el "¿qué me ha sucedido?” de Gregorio Samsa tras el despertar de un sueño, hay sólo eufemismo, la última y lábil peripecia del lenguaje antes de su retirada, de su ausencia: reírse de sí 
mismo; un gesto, una mueca, un guiño que intenta salvar -de algún modo- lo que queda de las circunstancias, como diría Ortega y Gasset en Meditaciones del Quijote (2001).

No sólo Lear o Samsa, Shakespeare o Kafka, sino que 'cualquiera' se encuentra expuesto a este gesto de lo que ocurre; la raspadura de nuestra existencia hasta gastarla en algo indefinido, indeterminado, impensado: el eufemismo de ser 'cualquiera', 'sea el que fuere', 'alguien', instala la tachadura de todo lo definido (legal, social, político, filosófico) del fundamento: ausencia de saber, ausencia de lenguaje, ausencia de sí; el margen -cualquiera- de todo humanismo.

Entre la incógnita de lo humano y la trinchera del poder, encontramos hoy al humanismo (tal vez siempre fue así), quizá esperando la última bala en un campo de batalla o en 'cualquiera', quizá esperando su salvación en la redención de un último eufemismo. Ambas perspectivas han sido el diapasón con el que se han afinado las palabras que suenan a 'humanismo', 'humano', 'comunidad'. De su significado aún no sabemos nada, sino sólo intenciones. No se sabe nada, ni de lo que pueda pasar e incluso de lo que ha pasado, puesto que aun en el pasado irrumpe el no-saber: damnatio memoriae, la tachadura de la memoria, el último y primer refugio del Humanismo.

La ausencia (la tachadura) de sentido (significado, fundamento, dirección) ante 'lo que ocurre', convierte la tachadura en un estado radical en el que el sentido se quiebra en lo in-humano': lo inabordable del humanismo, la radical ausencia del humanismo. Lo 'in-humano' habla 'en torno a un referente' (en torno a 'lo que ocurre', como si la única manera de decir lo que ocurre fuese desde los márgenes, allende el habla, allende el ser, allende la experiencia humana) antes del acontecimiento humano. No es la contradicción ni la oposición a 'lo humano': lo 'in-humano' es un estado que está más allá del bien y del mal -como bien afirma Nietzsche-, no es un atributo o un predicado que se deriva de 'lo humano' (ético o político), sino su ausencia radical, más indeterminada que la diferencia óntico-ontológica o que la existencia auténtica e inauténtica de Heidegger (1997), en la que ser y ente son meros referentes ante la 'ocurrencia de la nada'. No una ausencia en el sentido de falta o de 'incompletud de lo humano', sino ausencia de existencia en la que 'lo humano' no tiene aún existencia (o excusa de existir), en la tabula rasa de lo existente; una suerte de orgánica vegetalidad que nada sabe de sí, sin ton ni son, sin intencionalidad ni relación: la indiferencia imposible en el horizonte de una comunidad imposible (Blanchot, 1999). 
¿Quizá sea este 'in-humano' la preocupación central de Levinas, y por ello su intento de salvar 'lo humano' de la ausencia (lo in-humano, lo imposible)? ¿De ahí el llamado a la liberación de Sí Mismo, que en el fondo es liberarse de la indiferencia para situarse en el acontecimiento que posibilita la noindiferencia que constituye la experiencia de 'lo humano'? 'Lo humano' para Levinas comienza con la 'experiencia de relación', la no-indiferencia de estar 'el-uno-para-el-otro', la comunidad como 'otro-modo-que-ser'.

Por su parte, para Esposito la base de la constitución de la comunidad no sólo implica renunciar a lo propio (lugar de lo impropio), sino que opera también sobre el fondo de la ausencia (un simulacro de ausencia). Si en Levinas el trabajo es la liberación de Sí Mismo, en Esposito es en primer lugar la renuncia de lo personal, lo propio, la identidad, y luego la donación de sí. Sin embargo, el acto de renuncia es también un acto de donación (sacrificio, renuncia).

En la pérdida de la subjetividad 'se pone en común' la pérdida de la existencia subjetiva. Esto quiere decir que sólo tras el acto de renuncia deviene la donación (lo único que me queda para dar): si es lo existente 'lo que se da' para abrirse a su donación, ello sucede sólo posteriormente, tras la renuncia de la subjetividad. De acuerdo con Levinas, el existente vive en un constante conflicto que lo determina: frente al 'ya no-poder dar nada más', el existente "cae" en el espacio de lo impolítico, se arroja al conflicto de su existencia sin nada más que su vida, la ausencia subjetiva de poder. En el fondo, la donación queda determinada (marcada) por la finitud de la subjetividad, convirtiéndose en una consecuencia de la pérdida para dar forma a una comunidad que nace ante el rechazo (renuncia, rechazo del significante fundamental: el poder subjetivo) de la hegemonía de la subjetividad.

Al parecer lo que nuestros autores se han esforzado en señalar es que estamos sujetos a una situacionalidad en la que la incertidumbre sobredetermina todas nuestras preguntas y pensamientos. 'Lo humano' (del mismo modo que el lenguaje) no-sabe de su experiencia y simplemente se pierde en la banalidad del mundo (lo real), desprendiéndose de toda intencionalidad, de toda pretensión, de toda diferencia; convirtiéndose así en una simple palabra que evoca en su 'infinita trascendencia' un exceso, que no podríamos señalar si es de sentido o sin sentido, si es 'humano' o 'in-humano'. ¿Es el trasfondo de esta insuficiencia y su desproporción (exceso) lo que está en tensión en el juego de la incertidumbre de lo humano, o será el cuestionar la experiencia de sentido de lo humano como nos lo plantea el pensamiento levinasiano, donde 
el cuestionar la experiencia de sentido no solo nos orienta a la interrogación acerca de 'la experiencia humana', sino que también nos puede llevar a perderla en el sin sentido, convirtiendo a 'lo humano' en 'lo ausente'. Es probablemente debido a la "ausencia de humanismo", y no a su presencia lo cual resulta sintomático-, que creamos principios morales en la figura de Derechos Humanos, o cuestionamos la experiencia de sentido de 'lo humano' o de la communitas.

Lo relevante es observar que todo humanismo se sustenta en la indefensión de la idea que construimos del 'ser humano'; una idea que al tornarse más compleja a lo largo de los procesos históricos, políticos y culturales, tiende a apreciarse utilitariamente en función de las ideas positivistas de progreso y desarrollo humano. Y es quizá esta situación estructural (paradigmática) la que interfiere en el despliegue de nuevas interpretaciones que permitan comprender la 'experiencia humana', no como un sistema de relaciones (organización socio-política o cognitivista-conductual), sino como un acontecimiento que se abre a la comprensión y problematización de dichas relaciones. En este sentido, la comunidad es la instancia en la que dicha experiencia se ex-pone y conduce hasta el límite (márgenes) del lenguaje y del pensamiento; un desafío no sólo de carácter intelectual, sino también vivencial.

\section{Referencias}

Arendt, H. (2003). Eichmann en Jerusalem. (Trad. Ribalta, C.). Barcelona: Lumen.

Benjamin, W. (2002). La dialéctica en suspenso. Fragmentos sobre la historia. (Trad. Oyarzún, P.). Santiago de Chile: LOM.

Blanchot, M. (1999). La comunidad inconfesable. (Trad. Herrera, I.). Madrid: Arena.

Bordas, N. (1997). Filosofía a la intemperie. Buenos Aires: Biblos.

Castro, R. (2008). Foucault y el cuidado de la libertad. Santiago de Chile: LOM.

Deleuze, G. y Guatari, F. (1985). El Anti Edipo. (Trad. Monge, F.). Barcelona: Paidós. 
Deleuze, G. (2002). Diferencia y repetición. (Trad. Delpy, M.). Buenos Aires: Amorrortu.

Dörr, O. (1996). Espacio y tiempo vividos. Santiago de Chile: Editorial Universitaria.

Esposito, R. (2003). Communitas. Origen y destino de la comunidad. (Trad. Molinari M. R.). Buenos Aires: Amorrortu.

Foucault, M. (2000). Un diálogo sobre el poder. (Trad. Morey, M.). Madrid: Alianza.

Foucault, M. (2002). Arqueología del saber. (Trad. Garzón del Camino, A.). Buenos Aires: Siglo XXI.

Heidegger, M. (1997). Ser y tiempo. (Trad. Rivera, J.). Santiago de Chile: Editorial Universitaria.

Hobbes, Th. (1980). Leviatán o la invención moderna de la razón. (Trad. Escohotado, A.). Madrid: Editora Nacional.

Hobbes, Th. (2005). Elementos de Derecho natural y político. (Trad. Negro Pavón, D.). Madrid: Alianza.

Korstanje, M. (2009). El temor en Thomas Hobbes como organizador político: notas preliminares sobre la paradoja profesional. Revista Internacional de Filosofia, XV (2010), pp. 167-186.

Larraín, J. (2010). El concepto de Ideología: Postestructuralismo, Postmodernismo y Postmarxismo. Santiago de Chile: LOM.

Levinas, E. (1993a). El Humanismo del Otro Hombre. (Trad. González R. A.). Madrid: Caparrós Editores.

Levinas, E. (1993b). El tiempo y el Otro. (Trad. Pardo, J.). Barcelona: Paidós

Levinas, E. (1995). De Otro modo que ser, o más allá de la esencia. (Trad. Pintor, R. A.). Salamanca: Sígueme.

Levinas, E. (2001). Entre nosotros. Ensayos para pensar en otro. (Trad. Pardo, J.). Valencia: Pre-textos.

Nancy, J. L. (2000). La Comunidad Inoperante. (Trad. Garrido, J. M.). Santiago de Chile: Arces-LOM. 
Ortega y Gasset, J. (2001). Meditaciones del Quijote. Madrid: Cátedra.

Parra, N. (2004). Lear. Rey \& Mendigo. Santiago de Chile: Universidad Diego Portales.

Touraine, A. (2006). Crítica de la modernidad. (Trad. Bixio, A.). México: F.C.E.

Wiesel, E. y Baptist Metz, J. (1996). Esperar a pesar de todo. (Trad. Gauger, C.). Madrid: Trotta. 